\title{
Primary data
}

\author{
Trung Tran, Quy Khuc \\ CVietkap group, Hanoi, Vietnam \\ Preprint DOI: https://osf.io/f25v7
}

February 3, 2021

\begin{abstract}
Primary data is inherently the "king" element in the ecosystem of scientific research. Primary data was collected from primary data investigations. This work is not too difficult but requires strenuous efforts and considerable time from scientists, especially young ones with little experience in primary data investigation. Meanwhile, there are merely scant and unsystematic documents on primary data and its investigation methods. In this chapter, definition of primary data, primary data investigation methods and the procedure for data collection by questionnaires will be presented systematically.

Keywords: Keywords: Primary investigation, primary data, questionnaire method, model

\section{Introduction}

Data is information about things, events and phenomena, usually in numerical form. In an era of technology where data is deemed "king", the role that data plays has become increasingly important to all industries and fields alike [1,2]. With regard to scientific fields, data plays an even more important role: it is indispensable for research. This is because data contains information on the research subjects. Research papers on how to understand data, how to transform data into useful information, how to identify and solve data problems are derived from data itself.
\end{abstract}


So are ideas, discoveries and innovations. Thus, if scientists have trouble with the ingredient - data (inadequate or "unclean", for example), "cooking a decent meal" is out of the question for them.

In an era of information explosion, we have witnessed an exponential increase in data, along with the enhancement in data collection and processing, which is useful for scientists to access data sources [3]. However, this development also gives rise to difficulties in data organization and database design. Moreover, due to convenience and great assistance from technology, scientists are sometimes "lazy" to collect important information, given the considerable effort and cost required, yielding poor research outcomes. Research data is divided into primary and secondary data [4-6]. Since primary data is crucial and its collection is demanding, this chapter delves into the definition and investigation methods of primary data.

Primary data is original and first collected by researchers for the purpose of the study [7]. In each study, scientists sketch out necessary information and data on which to process, analyze and achieve the study's goal. For example, a phone brand plans to launch its latest product and wants to do a survey on the current trends in design and features of a phone. The company will select a group of people that matches the characteristics of its targeted market as a sample and conduct a primary data investigation. Based on the collected data, the company will come up with new directions to meet the general market and reap high profits.

Primary and secondary data are used collectively for highest efficiency. If secondary data is inherited and provides a foundation, primary data will add newness, update and correctness (Table 1). Obviously, primary data is of greater significance than secondary data owing to the following reasons. Firstly, primary data serves only one specific study [7-10], so the information received will perfectly match the study that scientists are implementing. Moreover, information from primary data sources is accurate and complete because it is collected originally and according to specifically designed content. 
Table 1. Comparison of primary and secondary data

\begin{tabular}{|c|c|c|}
\hline & Primary data & Secondary data \\
\hline Advantages & $\begin{array}{l}\text { - Data is "fresh" and is } \\
\text { collected directly. } \\
\text { - Investigation methods } \\
\text { are flexible to suit } \\
\text { research questions. } \\
\text { - Primary data directly } \\
\text { serves current research. } \\
\text { More specifically, data } \\
\text { collected helps researchers } \\
\text { in finding the bottom line } \\
\text { of the problem or in } \\
\text { predictive analytics. }\end{array}$ & $\begin{array}{l}\text { - Easy to find as the data is available } \\
\text { from previous studies. } \\
\text { - The cost of collecting data is cheap, } \\
\text { sometimes free, such as data on } \\
\text { websites. For example, Statistical } \\
\text { Yearbook is a cheap secondary data } \\
\text { source. } \\
\text { - Ready and suitable (does not take } \\
\text { much time analyzing and evaluating. } \\
\text { - Secondary data adds value to primary } \\
\text { information, especially in clarifying } \\
\text { issues, specifying research objectives } \\
\text { and choosing primary data, which save } \\
\text { time and effort, as well as improve the } \\
\text { quality of primary information } \\
\text { collection. }\end{array}$ \\
\hline Disadvantages & $\begin{array}{l}\text { - High cost. } \\
\text { - Time-consuming } \\
\text { - Primary data only } \\
\text { serves a specific need at } \\
\text { a specific time, thus } \\
\text { sometimes requiring } \\
\text { combining } \\
\text { secondary with } \\
\text { investigation. }\end{array}$ & $\begin{array}{l}\text { - Scales of measurement might be } \\
\text { inconsistent with research objectives. } \\
\text { - Content might be inappropriate. } \\
\text { Previously collected information is } \\
\text { inconsistent with research objectives. } \\
\text { - Information is outdated and of poor } \\
\text { quality. } \\
\text { - The data source is not original, } \\
\text { thereby decreasing accuracy, which } \\
\text { could be attributed to copying and } \\
\text { processing the information for other } \\
\text { purposes. }\end{array}$ \\
\hline
\end{tabular}

As primary data is crucial, its investigation and collection must be done with meticulous attention and precision. In terms of methods, researchers can employ three primary data collection methods: observations, experiments, surveys. Each 
method has its own advantages and disadvantages, so depending on the topic and field of study, researchers will choose suitable research methods [5,7-14]. To be specific, observations are often used for behavioral science research or abstract research problems that are hard to quantify, experiments for study of natural sciences, medicine and engineering, surveys for quantitative research. We will go into detail about the survey method.

\section{Procedures of primary data collection}

The survey method takes a great deal of time and effort to obtain data. Thus, with a view to capturing the most accurate data source, a proper procedure must be complied with. Figure 1 presents the procedure for conducting a complete primary data survey, consisting of the following 5 steps. The first step is to design the questionnaire [15]. The questionnaire is designed based on the research objectives and subject. In the second step, the questionnaire is moved to the focus group in order to be screened and adjusted. The third step is to conduct a small pilot survey [11] to evaluate the questionnaire and to adjust the questionnaire again in order to fit reality. Step 2 and step 3 repeat yet complement each other with a shared view to editing and creating a "perfect" questionnaire before employing it for the next step (step 4). The fourth step is the formal investigation. The final step is to digitalize the collected information, so that we can carry out analysis. The detailed description of each step will be provided in the next chapter.

Figure 1. Procedure for data collection

Besides a proper procedure, human factors are of immense importance in an investigation. A wealth of knowledge and skills is critical for data collectors to create a primary data set that is deemed "qualified". Of all attributes, honesty is the salient feature in data surveys in general and in primary data investigations in particular. Next is teamwork, management and generalization skills. Given the enormous time and effort involved in primary data investigation, researchers must be motivated and able to motivate others, "keep the fire burning", so that the collected data is ensured both qualitatively and quantitatively. In addition, communication skills are also crucial when interacting with interviewees. That the investigator can create a 
comfortable and relaxed ambience and keep up the volunteer spirit of the interviewees helps to maintain objectivity and accuracy. Moreover, during the investigation, unexpected events or unfavorable situations might arise and disrupt the process, thereby affecting the data source. Hence, problem solving skills are also essential.

To sum up, in this chapter, we have discussed the role and meaning of primary data and illustrated the general procedure of primary data investigation. In the next chapters, main steps involved in a complete investigation will be elucidated.

\section{Review questions:}

1. What is data, primary data and secondary data?

2. What are the advantages and disadvantages of primary and secondary data?

3. How many main steps are there in the procedure for a complete primary data set? Name them.

\section{References}

[1] V. Rao, Data is king. The one who masters Data with Science will rule the World! So are You Ready for Data Science?, Linkedin. (2018). https://www.linkedin.com/pulse/data-king-one-who-masters-rule-world-soyou-ready-vinay-rao-mle-/ (accessed February 2, 2021).

[2] Q.H. Vuong, V.P. La, T.T. Vuong, M.T. Ho, H.K.T. Nguyen, V.H. Nguyen, H.H. Pham, M.T. Ho, Data descriptor: An open database of productivity in Vietnam's social sciences and humanities for public use, Sci. Data. 5 (2018) 1-15. https://doi.org/10.1038/sdata.2018.188.

[3] Editorial Team, The Exponential Growth of Data, Insidebigdata. (2017) https://www.un.org/en/sections/issues-depth/big-da. https://insidebigdata.com/2017/02/16/the-exponential-growth-ofdata/\#: :text=Human- and machine-generated data,growth toward 2020 and beyond. (accessed February 2, 2021).

[4] V.C. Dam, Phuong phap luan nghien cuu khoa hoc (Scientific research methodology), NXB Khoa hoc ky thuat, Hanoi, Vietnam, 1999.

[5] R.B. Uma Sekaran, Research Methods For Business: A Skill Building 
Approach, 7th Edition, 2016. https://doi.org/10.1007/978-94-007-07535_102084.

[6] J.J. Hox, H.R. Boeije, Data Collection, Primary vs. Secondary, Encycl. Soc. Meas. (2004) 593-599. https://doi.org/10.1016/B0-12-369398-5/00041-4.

[7] Kennethe D. Bailey, Methods of Social Research, fourth ed., The Free Press, New York, USA., 1994.

[8] Q. Van Khuc, T.V. Phu, P. Luu, Dataset on the Hanoian suburbanites' perception and mitigation strategies towards air pollution, Data Br. 33 (2020) 106414. https://doi.org/10.1016/j.dib.2020.106414.

[9] Q. Van Khuc, T.A.T. Le, T.H. Nguyen, D. Nong, B.Q. Tran, P. Meyfroidt, T. Tran, P.B. Duong, T.T. Nguyen, T. Tran, L. Pham, S. Leu, N.T. Phuong Thao, N. Huu-Dung, T.K. Dao, N. Van Hong, B.T. Minh Nguyet, H.S. Nguyen, M.W. Paschke, Forest cover change, households' livelihoods, tradeoffs, and constraints associated with plantation forests in poor upland-rural landscapes: Evidence from north central Vietnam, Forests. 11 (2020). https://doi.org/10.3390/F11050548.

[10] Q.H. Vuong, T.K. Nguyen, Data on Vietnamese patients' financial burdens and risk of destitution, Data Br. 9 (2016) 543-548. https://doi.org/10.1016/j.dib.2016.09.040.

[11] P.A. Champ, K.J. Boyle, T.C. Brown, A Primer on Nonmarket Valuation, 2017. http://link.springer.com/10.1007/978-94-007-7104-8.

[12] V.T. Nguyen, Tu nghien cuu den cong bo (from research to publication), NXB tong hop tp Ho Chi Minh, Ho Chi Minh city, Vietnam, 2013.

[13] Q. Van Khuc, M. Alhassan, J.B. Loomis, T.D. Tran, M.W. Paschke, Estimating Urban Households' Willingness-to-Pay for Upland Forest Restoration in Vietnam, Open J. For. 06 (2016) 191-198. https://doi.org/10.4236/ojf.2016.63016.

[14] Q.H. Vuong, Data Descriptor: Survey data on Vietnamese propensity to attend periodic general health examinations, Sci. Data. 4 (2017) 1-10. https://doi.org/10.1038/sdata.2017.142.

[15] Bill Gillham, Developing a Questionnaire, CONTINUUM, London, UK, 2000. 